\title{
Development of an Innovative Pressurized Liquid Extraction Procedure by Response Surface Methodology to Recover Bioactive Compounds from Carao Tree Seeds
}

\author{
Jhunior Abrahan Marcía Fuentes ${ }^{1,2,+}+\mathbb{C}$, Lucía López-Salas ${ }^{3,+}{ }^{+}$Isabel Borrás-Linares ${ }^{4, *}$, \\ Miguel Navarro-Alarcón ${ }^{3}\left(\mathbb{D}\right.$, Antonio Segura-Carretero ${ }^{4,5, \ddagger}$ and Jesús Lozano-Sánchez ${ }^{3,4, \mp(1)}$ \\ 1 Faculty of Technological Sciences, Universidad Nacional de Agricultura, Catacamas, \\ Olancho 16201, Honduras; juniorabrahamm@yahoo.com \\ 2 Faculty of Pharmacy and Food, University of Havana, La Lisa 17100, Havana, Cuba \\ 3 Department of Food Science and Nutrition, University of Granada, Campus Universitario s/n, \\ 18071 Granada, Spain; lslucia@correo.ugr.es (L.L.-S.); nalarcon@ugr.es (M.N.-A.); jesusls@ugr.es (J.L.-S.) \\ 4 Functional Food Research and Development Centre (CIDAF), Health Sciencie Technological Park, \\ Avda. Del Conocimiento s/n, 18016 Granada, Spain; ansegura@ugr.es \\ 5 Department of Analytical Chemistry, Faculty of Sciences, University of Granada, 18071 Granada, Spain \\ check for \\ updates \\ Citation: Fuentes, J.A.M.; \\ * Correspondence: iborras@cidaf.es; Tel.: +34-958637083 \\ + Both authors contributed equally. \\ $\ddagger$ These authors are joint senior authors on this work.
}

López-Salas, L.; Borrás-Linares, I.;

Navarro-Alarcón, M.;

Segura-Carretero, A.;

Lozano-Sánchez, J. Development of an Innovative Pressurized Liquid Extraction Procedure by Response Surface Methodology to Recover Bioactive Compounds from Carao Tree Seeds. Foods 2021, 10, 398. https://doi.org/10.3390/ foods10020398

Academic Editor: Elisabete M. C. Alexandre, Jorge Manuel Alexandre Saraiva and Manuela Pintado

Received: 13 January 2021

Accepted: 8 February 2021

Published: 11 February 2021

Publisher's Note: MDPI stays neutral with regard to jurisdictional claims in published maps and institutional affiliations.

Copyright: (c) 2021 by the authors. Licensee MDPI, Basel, Switzerland. This article is an open access article distributed under the terms and conditions of the Creative Commons Attribution (CC BY) license (https:/ / creativecommons.org/licenses/by/ $4.0 /)$.

\begin{abstract}
Nowadays there are evidences from several studies which have revealed the protective effects of food against chronic diseases. These healthy properties have been related to bioactive compounds. Among bioactive substances, the scientific interest in phenolic compounds has stimulated multidisciplinary research on the composition of plant phenolic compounds. The aim of this work has been to determine the bioactive composition of Carao tree seeds (Cassia grandis) and to optimize the recovering of these compounds for developing functional ingredients. To achieve this goal, pressurized liquid extraction (PLE) has been applied to recover these phytochemicals. The optimization of this innovative extraction procedure was performed by a response surface methodology (RSM) based on a central composite design $2^{3}$ model to address the bioactive compounds extraction. Phenolic compounds recovered by PLE were characterized using reversed-phase high-performance liquid chromatography coupled to electrospray ionization time-of-flight mass spectrometry (HPLCESI-TOF-MS). Analytical characterization allowed the identification and quantitation of phenolic compounds belonging to hydroxybenzoic acids and flavonoids (flavonols, flavanols, flavanones and proanthocyanidins). Phytochemical concentrations were used as response variable in order to get the best extraction conditions. These results pointed out that Carao tree seeds can be a potential source of bioactive compounds and PLE extracts could be used as functional ingredients.
\end{abstract}

Keywords: carao tree seeds; phenolics; PLE; HPLC-MS; bioactive compounds

\section{Introduction}

Nowadays, the well-known relationship between diet-health has generated a lot of interest among current consumers, who are looking for healthy foods. In this sense, fruits and vegetables are highly appreciated for their health benefits, which are directly linked to the high number of biologically active components present in their composition. These substances, called bioactive phytochemicals or bioactive compounds, possess different nature and very diverse structures. Among these, phenolic compounds, which are considered secondary metabolites of plants, have increased the scientific interest in different areas [1,2]. Phenolic compounds can be classified into two different types: simple phenols and polyphenols. Phenolic acids (benzoic and cinnamic acids) and benzoquinones are part of the group of simple phenols, while polyphenols include flavonoids, stilbenes, lignans, 
tannins and other polymerized compounds. Regarding flavonoids, they deserve special attention due to their widely chemical groups: chalcones, dihydrochalcones, flavonols, dihydroflavonols, flavonoids (flavan-3-ols), flavones, flavanones, isoflavonoids and anthocyanidins. The bioactive properties that have been attributed to phenolic compounds are diverse, and their antioxidant capacity is the best-known effect $[3,4]$. In addition, other properties have been described such as anticancer, anti-inflammatory, antihypertensive, estrogenic, protective effects against cardiovascular disease, anti-hormone, antidiabetic and antithrombotic, among others [5,6].

Recovering of phenolic compounds from many parts of plants have been carried out to develop functional ingredients. To achieve this goal, new techniques have been introduced to improve the extraction process, such as pressurize liquid extraction (PLE). PLE allows to get natural extracts from plants combining elevated temperature and pressures with solvents to achieve fast and efficient extraction with a wide range of compounds polarities [7]. Indeed this technique has been applied to recover this kind of phytochemicals from different vegetables, fruits and oils as well as the by-products generated over the production process i.e., Hibiscus sabdariffa calyces, Sclerocarya birrea stem, pomegranate peel, weet cherry stem, and olive oil by-products [8-14]. In these studies, response surface methodology (RSM) was applied to optimize the phytochemical recovering, since its combination with advanced extraction technique may enhance the bioactive-extract production process. Consequently, RSM coupled to PLE provide a simply way to understand the extraction process as well as to reach the optimum conditions to increase the phenolic compounds extraction efficiency from vegetable matrices.

Cassia grandis, also known as "carao" and commonly called "pink shower", is a tree of the Fabaceae family native from Central and South America. It is a medium-sized tree that matures to $15-30 \mathrm{~m}$ tall characterized by producing large pinnate leaves, a spectacular bloom with striking coral pink flowers that appear in early spring (hence its name "pink shower") and large bean-shaped seed pods. After blooming, the flowers are replaced by thin woody pods that grow up to 2 and 3 inches long, containing between 70 and 80 seeds per pod. Inside the pods, the seeds are oriented transversely and separated into individual cells. In each partition there is a round, flattened, tan colored seed, which is surrounded by a dark brown, sticky, bittersweet pulp with a strong smell. For its shade, this tree is planted as an ornamental tree in gardens and avenues [15].

C. grandis is considered as food since its pods are edible for humans and in Central America the seed membrane, is used as a chocolate substitute. Scientific reports have pointed out the antioxidant properties of Carao seeds, which explains its use in traditional medicine [16]. Part of these functions could be related to its composition in bioactive compounds like simple phenols, flavonoids and tannins [16]. Indeed, different authors have reported the biological activity of phytochemicals belonging to these chemical groups $[1,6]$. Since scientific knowledge has pointed out that enriched extracts in this kind of phenolic compounds have interesting technological and pharmaceutical properties, they could be applied to develop food antioxidants or as ingredients in nutraceutical products.

The aim of this research was to analyze and optimize the extraction of the phenolic profile from C. grandis seeds through the combination of advanced extraction system and analytical platform. Response surface methodology was applied to obtain PLE enriched extracts which were characterized by high-performance liquid chromatography coupled to electrospray ionization time-of-flight mass spectrometry (HPLC-ESI-TOF-MS).

\section{Materials and Methods}

\subsection{Reagents}

All reagents used in this work were of analytical reagent grade. For extraction procedure, water used as solvent was purified by a Milli-Q system from Millipore (Bedford, MA, USA) and ethanol were purchased from VWR Chemicals (Radnor, PA, USA). Sand and cellulose filters were purchased from Fisher Chemicals (Waltham, MA, USA). For mobile phase preparation, formic acid was provided by Sigma-Aldrich (Steinheim, Ger- 
many) and LC-MS-grade acetonitrile was purchased from Fisher Chemicals (Waltham, MA, USA). The standards for the calibration curves (gallic acid, catechin, epicatechin, epigallocatechin-gallate, quercetn-3-glucoside and kaempferol-3-rutinoside) were acquired from Fluka, Sigma-Aldrich (Steinheim, Germany) or Extrasynthese (Genay Cedex, France).

\subsection{Plant Material}

Fresh samples of the carao fruit (C. grandis) were randomly collected in the wild with optimal maturity in the Guapinol Biological Reserve, Marcovia Municipality, Choluteca Department (Honduras), between February and March 2020. The total amount of the collected samples was $100 \mathrm{~kg}$. Manual separation was carried out in different parts and the seeds were dried in an air circulation oven (Digitronic TFT- Selecta, J.P. SELECTA, Barcelona, Spain), during $48 \mathrm{~h}$ at $50^{\circ} \mathrm{C}$. Then, seeds were ground with a Retsch SM-100 brand blade mill (Retsch), equipped with a sieve from 501 to $700 \mu \mathrm{m}$, and vacuum packed. The processed samples were preserved at room temperature $\left(30^{\circ} \mathrm{C} \pm 5{ }^{\circ} \mathrm{C}\right)$ until the extraction process.

\subsection{Pressurized Liquid Extraction}

Recovery of phytochemicals was carried out using a Dionex ASE 350 Accelerated Solvent Extractor (Dionex Corp., Sunnyvale, CA, USA). Extractions were done with different experimental combinations among solvent composition (ethanol and water), temperatures and extraction time. All extractions were carried out at constant pressure (11 MPa) and under a $\mathrm{N}_{2}$ atmosphere.

To carry out the extractions, the solvents were previously degassed for $15 \mathrm{~min}$ to remove the dissolved oxygen in order to avoid any possible oxidation. For each extraction, $3 \mathrm{~g}$ of sample were mixed with $9 \mathrm{~g}$ of sand and loaded onto $33 \mathrm{~mL}$ stainless-steel extraction cells. The chosen configuration was sandwich type $(5 \mathrm{~g}$ sand + mixture sample - sand + $5 \mathrm{~g}$ sand). Cellulose filters were placed at each end of the cell in order to prevent clogging of the metal frits. The extraction conditions described above were applied and the obtained extracts were collected in glass vials. These extracts were quickly cooled to room temperature, filtered, and vacuum evaporated using a Savant SpeedVac Concentrator SC250EXP (Thermo Scientific, Sunnyvale, CA, USA) and stored at $-20^{\circ} \mathrm{C}$ until HPLC analysis.

\subsection{Design of Experiments}

Response surface methodology (RSM) was used to evaluate the effect of PLE parameters on retrieval and yield of phenolic compounds, using Statgraphics Centurion XV software version 15.1.02. The applied design model was a central composite design $2^{3}$ (CCD) model with two axial points and two levels (maximum and minimum) for each independent variable. Temperature, percentage of ethanol and extraction time were chosen for independent variables, and the experimental design consisted of a total of 14 experiments that were performed in a randomized order (Table 1). The experimental design covered the entire operational range of the temperature and solvent ratio that the device allows.

Response variables were the chemical composition of the extracts determined by HPLC-ESI-TOF-MS and yield. The extraction yield of each procedure was calculated considering the weight of dried extract and the amounts of carao seed used in the procedure (Equation (1)):

$$
\text { Yield }(\%)=\frac{\text { Weight of dried extract }(\mathrm{g})}{\text { Weight of dried seeds used }(\mathrm{g})} \times 100
$$

The obtained results were integrated into the experimental design with the Statgraphics Centurion 15.0 software. The adequacy of the model obtained for PLE were checked by evaluating coefficient of determination $\left(R^{2}\right)$, coefficient of variation $(\mathrm{CV})$ and the Fisher's test value (F-ratio). Significant values were considered when $p<0.05$. Equations of the model adjusted for extraction yield and content in total phenolic compounds were obtained according to a second-order polynomial model. The 3D response surface plots allowed 
visualizing the relationship between independent variables and responses, representing the dependent variables in function of two most influent independent variables. Optimum conditions were calculated considering the maximization of individual response variables.

Table 1. Central composite model $2^{3}$. Values of independent factors.

\begin{tabular}{cccc}
\hline Experimental Condition & Temperature $\left({ }^{\circ} \mathbf{C}\right)$ & \%EtOH & $\begin{array}{c}\text { Static Cycle } \\
\text { (min) }\end{array}$ \\
\hline PLE 1 & 40 & 15 & 20 \\
PLE 2 & 40 & 85 & 5 \\
PLE 3 & 110 & 5 & 12.5 \\
PLE 4 & 110 & 50 & 22 \\
PLE 5 & 40 & 15 & 5 \\
PLE 6 & 20 & 50 & 12.5 \\
PLE 7 & 110 & 50 & 3 \\
PLE 8 & 110 & 50 & 12.5 \\
PLE 9 & 110 & 50 & 12.5 \\
PLE 10 & 40 & 85 & 20 \\
PLE 11 & 180 & 85 & 5 \\
PLE 12 & 180 & 85 & 20 \\
PLE 13 & 110 & 95 & 12.5 \\
PLE 14 & 200 & 50 & 12.5 \\
\hline
\end{tabular}

Temperature levels $\left({ }^{\circ} \mathrm{C}\right):-\alpha, \alpha(20,200),-1,1(40,180)$ and $0(110)$. EtOH levels $(\%):-\alpha, \alpha(5,95),-1,1(15,85)$ and 0 (50). Static cycle levels (min): $-\alpha, \alpha(3,22),-1,1(5,20)$ and $0(12.5)$.

\subsection{HPLC-ESI-TOF-MS Analysis}

The PLE extracts were analyzed with an RRLC 1200 system (Agilent Technologies, Palo Alto, CA, USA), equipped with a vacuum degasser, a binary pump, an automated sampler, a thermostatic column compartment and a Diode Array Detector (DAD). The analytical column used for chromatographic separation was a $150 \mathrm{~mm} \times 4.6 \mathrm{~mm}$ id, $1.8 \mu \mathrm{m}$ particle diameter Zorbax Eclipse Plus C18 column (Agilent Technologies, Palo Alto, CA, USA). The mobile phase was $0.1 \%$ formic acid in water as eluent $\mathrm{A}$ and acetonitrile as eluent B. The injection volume was $10 \mu \mathrm{L}$. The flow rate of the mobile phase was $0.5 \mathrm{~mL} / \mathrm{min}$ and the column temperature was maintained at $25^{\circ} \mathrm{C}$. Total run time was 45 min with a multi-step linear gradient applied for the phytochemical separation: $0 \mathrm{~min}, 5 \% \mathrm{~B} ; 15 \mathrm{~min}$, $65 \% \mathrm{~B} ; 36 \mathrm{~min}, 95 \% \mathrm{~B} ; 40 \mathrm{~min}, 5 \% \mathrm{~B}$, and, then, a conditioning cycle of 5 min with the initial conditions before the next injection.

The HPLC system was coupled to an electro-spray time-of-flight mass spectrometer (HPLC-ESI-TOF-MS). The flow rate that reached the TOF-MS detector was $125 \mu \mathrm{L} / \mathrm{min}$. Detection was performed in negative-ion mode over a range from 50 to $1000 \mathrm{~m} / \mathrm{z}$. The values of the source parameters were: capillary voltage of $+4.5 \mathrm{kV}$; drying gas temperature, $190{ }^{\circ} \mathrm{C}$; drying gas flow, $9 \mathrm{~L} \mathrm{~min}{ }^{-1}$; and nebulizing gas pressure, 2.0 bar. The values of transfer parameters were: capillary exit, $-150 \mathrm{~V}$; skimmer 1, $-50 \mathrm{~V}$; hexapole 1, $-23 \mathrm{~V}$; RF hexapole, $100 \mathrm{Vpp}$; and skimmer 2, $-22.5 \mathrm{~V}$.

External mass-spectrometer calibration was performed using a 74900-00-05 Cole Palmer syringe pump (Vernon Hills, IL, USA) directly connected to the interface, equipped with a sodium formate solution $10 \mathrm{Mm}$. The mixture was injected at the beginning of each analysis and all spectra were calibrated before to the compounds identification. The exact mass data of the molecular ions were processed by Data Analysis 4.0 software (Bruker Daltonics, Billerica, MA, USA), which provided a list of possible elementary formulas using Generate-Molecular Formula Editor.

To carry out the identification and quantification of the analytes present in the PLE extracts, the samples were prepared at a concentration of $5 \mathrm{mg} / \mathrm{mL}$ using the hydroalcoholic mixture of ethanol and water (50:50, v:v) as solvent. Each extract was analyzed in triplicate. To carry out the quantitative analysis, calibration curves of the six standards described in the reagents section were prepared at a concentration of $1 \mathrm{mg} / \mathrm{mL}$. In order 
to draw the calibration curve for each standard compound, dilutions were prepared and analyzed at the following concentrations: $0.5 ; 1 ; 2.5 ; 10 ; 20 ; 30 ; 50 ; 75 ; 100$ and $150 \mathrm{ug} / \mathrm{mL}$.

\section{Results}

\subsection{Identification of Polar Compounds in PLE Extracts of C. grandis by HPLC-ESI-TOF-MS}

The compounds were identified by the data provided by HPLC-ESI-TOF-MS. The mass spectra obtained for the different PLE extracts were compared with the spectra of the available standards, so it was possible to identify some of the compounds present in the sample. All other compounds for which commercial standards were not available were identified by DataAnalysis 4.0 software. This software provided a list of possible elementary formulas by using the Generate-Molecular Formula Editor. The search of the formulas generated in the literature made it possible to identify a large number of chromatographic peaks obtained in the HPLC-MS chromatogram.

Most of the studies used in identifying these compounds were those that evaluated the chemical composition of other species of the genus Cassia, Fabaceae family or specimens of the same C. grandis class [9-22].

Figure 1 showed a base peak chromatogram (BPC) representative of the carao seed extracts obtained by HPLC-ESI-TOF-MS in negative polarity. A total of 47 compounds were detected and included in Table 2 that summarized the following information: retention time, experimental and theoretical $\mathrm{m} / \mathrm{z}$, error (ppm), mSigma, molecular formula, a list of proposed compounds as well as the extraction conditions in which the compounds were characterized. The identified compounds were tentatively identified as disaccharides, hydroxybenzoic acids, flavonoids, steroids and quinones. The mass spectra of these compounds are shown in Supplementary Figures S1 and S2. Despite that the information reported by the analysis of the extracts, it was not enough to the identification of some of these peaks, which being listed as unknown.

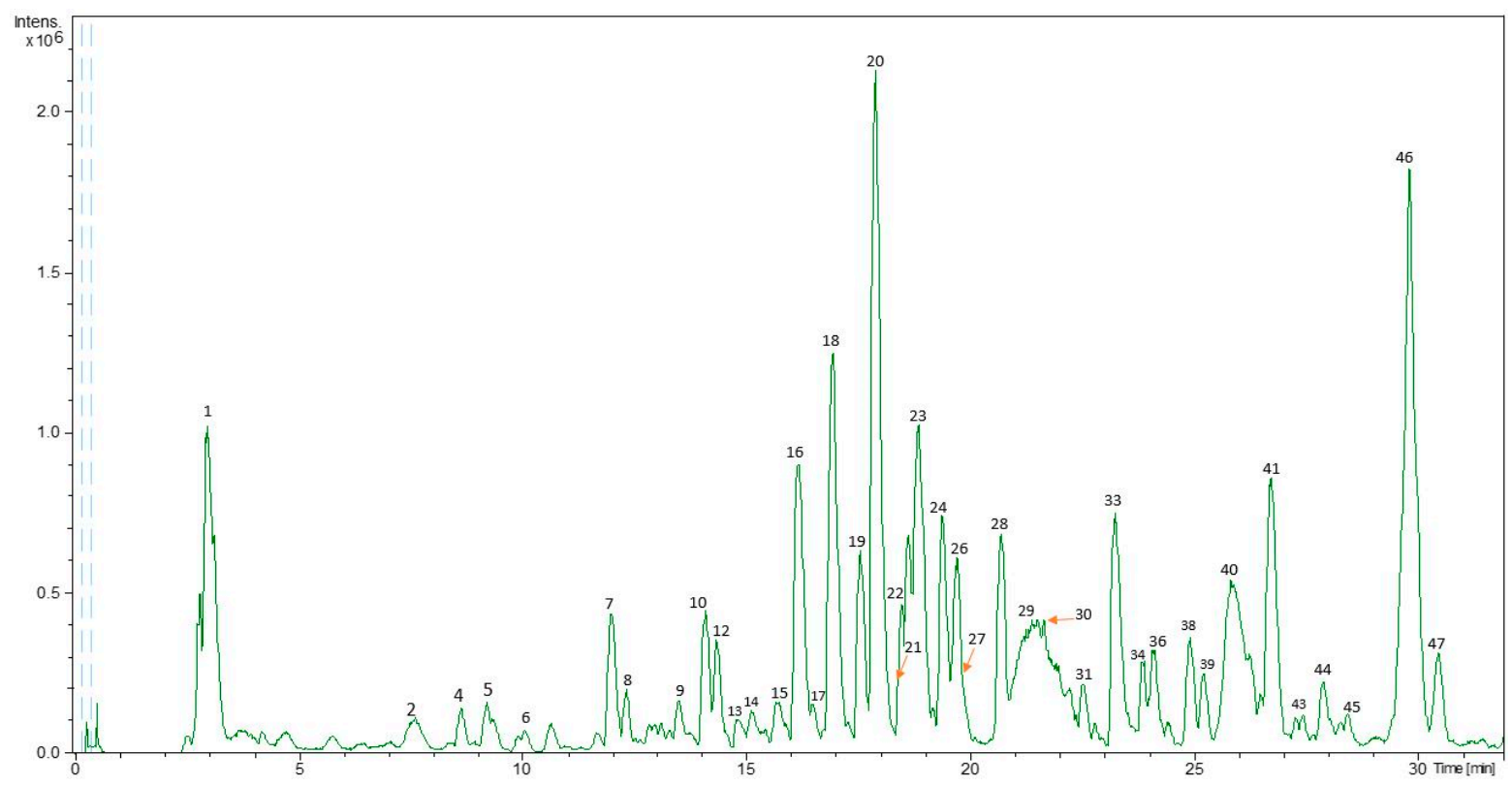

Figure 1. Base peak chromatogram (BPC) of representative pressurized liquid extraction (PLE) extract obtained by high-performance liquid chromatography coupled to electrospray ionization time-of-flight mass spectrometry (HPLC-ESITOF-MS). 
Table 2. Phenolic and other polar compounds of C. grandis PLE extracts characterized by HPLC-ESI-TOF-MS.

\begin{tabular}{|c|c|c|c|c|c|c|c|c|}
\hline Peak & RT (min) & Proposed Compound & $m / z$ & $m / z \operatorname{Exp}$ & Molecular Formula & Error (ppm) & mSigma & PLE \\
\hline 1 & 2.96 & Sucrose & 341.1089 & 341.1171 & $\mathrm{C}_{12} \mathrm{H}_{22} \mathrm{O}_{11}$ & -6.1 & 36.4 & * \\
\hline 2 & 7.59 & Galloyl glucoside & 331.0671 & 331.0696 & $\mathrm{C}_{13} \mathrm{H}_{16} \mathrm{O}_{10}$ & 2.0 & 11.8 & * \\
\hline 3 & 8.40 & Galloyl glucoside derivative & 315.0722 & 315.0675 & $\mathrm{C}_{13} \mathrm{H}_{16} \mathrm{O}_{9}$ & 3.3 & 5.7 & $1,3,4,5,6,7,8,11$ \\
\hline 5 & 9.20 & UK2 & 380.1562 & 380.1574 & $\mathrm{C}_{15} \mathrm{H}_{26} \mathrm{NO}_{10}$ & -0.5 & 6.0 & 2,10 \\
\hline 6 & 10.05 & UK3 & 371.0925 & 371.0993 & $\mathrm{C}_{23} \mathrm{H}_{16} \mathrm{O}_{5}$ & -13.4 & 32.6 & $\begin{array}{c}1,2,3,4,5,6,7,8 \\
9,10,11,12,13\end{array}$ \\
\hline 7 & 11.99 & UK4 & 443.1923 & 443.1963 & $\mathrm{C}_{21} \mathrm{H}_{32} \mathrm{O}_{10}$ & -8.8 & 3.6 & $*$ \\
\hline 9 & 13.48 & Theaflavin derivative & 771.2353 & 771.2391 & $\mathrm{C}_{34} \mathrm{H}_{44} \mathrm{O}_{20}$ & 5.8 & 3.9 & * \\
\hline 10 & 14.10 & UK5 & 541.2173 & 541.2179 & $\mathrm{C}_{40} \mathrm{H}_{29} \mathrm{O}_{2}$ & 6.5 & 72.4 & * \\
\hline 11 & 14.23 & Catechin & 289.0718 & 289.0734 & $\mathrm{C}_{15} \mathrm{H}_{14} \mathrm{O}_{6}$ & -9.6 & 9.5 & $\begin{array}{c}3,4,5,8,9,11,12 \\
14\end{array}$ \\
\hline 12 & 14.33 & (Epi)gallocatechin-(epi)catechin or isomer 2 & 593.1301 & 593.1523 & $\mathrm{C}_{30} \mathrm{H}_{26} \mathrm{O}_{13}$ & -18.9 & 28.4 & $*$ \\
\hline 13 & 14.82 & Procyanidin derivative & 579.1508 & 579.1728 & $\mathrm{C}_{30} \mathrm{H}_{27} \mathrm{O}_{12}$ & -19.5 & 11.8 & $\begin{array}{c}1,2,3,4,7,8,9,10 \\
12,13\end{array}$ \\
\hline 14 & 15.12 & (Epi)catechin-(epi)catechin & 577.1351 & 577.1368 & $\mathrm{C}_{30} \mathrm{H}_{26} \mathrm{O}_{12}$ & 5.8 & 8.4 & $\begin{array}{c}1,2,3,4,5,6,7,8 \\
9,10,11,13\end{array}$ \\
\hline 16 & 16.17 & (Epi)-catechin & 289.0718 & 289.0786 & $\mathrm{C}_{15} \mathrm{H}_{14} \mathrm{O}_{6}$ & -10.3 & 2.1 & $*$ \\
\hline 17 & 16.47 & Astilbin & 449.1089 & 449.1109 & $\mathrm{C}_{21} \mathrm{H}_{22} \mathrm{O}_{11}$ & 2.9 & 6.4 & * \\
\hline 18 & 16.94 & Pinocembrin 7-neohesperidoside & 563.1770 & 563.1743 & $\mathrm{C}_{27} \mathrm{H}_{32} \mathrm{O}_{13}$ & 5.3 & 14.1 & * \\
\hline 19 & 17.54 & UK7 & 563.1864 & 563.1822 & $\mathrm{C}_{38} \mathrm{H}_{28} \mathrm{O}_{5}$ & 7.3 & 10.6 & * \\
\hline 20 & 17.91 & Pinocembrin 7-rutinoside & 563.1770 & 563.1778 & $\mathrm{C}_{27} \mathrm{H}_{32} \mathrm{O}_{13}$ & -14.5 & 12.8 & * \\
\hline 21 & 18.41 & (Epi)-afzelechin or isomer 1 & 273.0768 & 273.0777 & $\mathrm{C}_{15} \mathrm{H}_{14} \mathrm{O}_{5}$ & -1.8 & 36.9 & * \\
\hline 22 & 18.50 & Cassanidin A & 817.2138 & 817.2133 & $\mathrm{C}_{45} \mathrm{H}_{38} \mathrm{O}_{15}$ & 6.8 & 9.8 & * \\
\hline 23 & 18.85 & (Epi)-guibourtinidol-(epi)-catechin or isomer 1 & 545.1453 & 545.1547 & $\mathrm{C}_{30} \mathrm{H}_{26} \mathrm{O}_{10}$ & -13.1 & 40.4 & * \\
\hline 24 & 19.32 & UK8 or isomer 1 & 553.2232 & 553.2200 & $\mathrm{C}_{34} \mathrm{H}_{33} \mathrm{O}_{7}$ & 2.4 & 6.6 & $2,3,5,6,10$ \\
\hline 25 & 19.37 & (Epi)-afzelechin or isomer 2 & 273.0768 & 273.0840 & $\mathrm{C}_{15} \mathrm{H}_{14} \mathrm{O}_{5}$ & -15.8 & 7.2 & 11,12 \\
\hline 26 & 19.70 & UK8 or isomer 2 & 553.2232 & 553.2195 & $\mathrm{C}_{34} \mathrm{H}_{33} \mathrm{O}_{7}$ & 4.9 & 9.8 & $2,3,6,10$ \\
\hline 27 & 19.77 & Quercentin-3-glucoside & 463.0882 & 463.0894 & $\mathrm{C}_{21} \mathrm{H}_{20} \mathrm{O}_{12}$ & -2.1 & 34.0 & $\begin{array}{c}1,3,4,5,6,7,8,9 \\
10,11,12,13,14\end{array}$ \\
\hline 28 & 20.67 & Physalin A & 525.1766 & 525.1672 & $\mathrm{C}_{28} \mathrm{H}_{30} \mathrm{O}_{10}$ & 17.0 & 17.3 & $*$ \\
\hline
\end{tabular}


Table 2. Cont

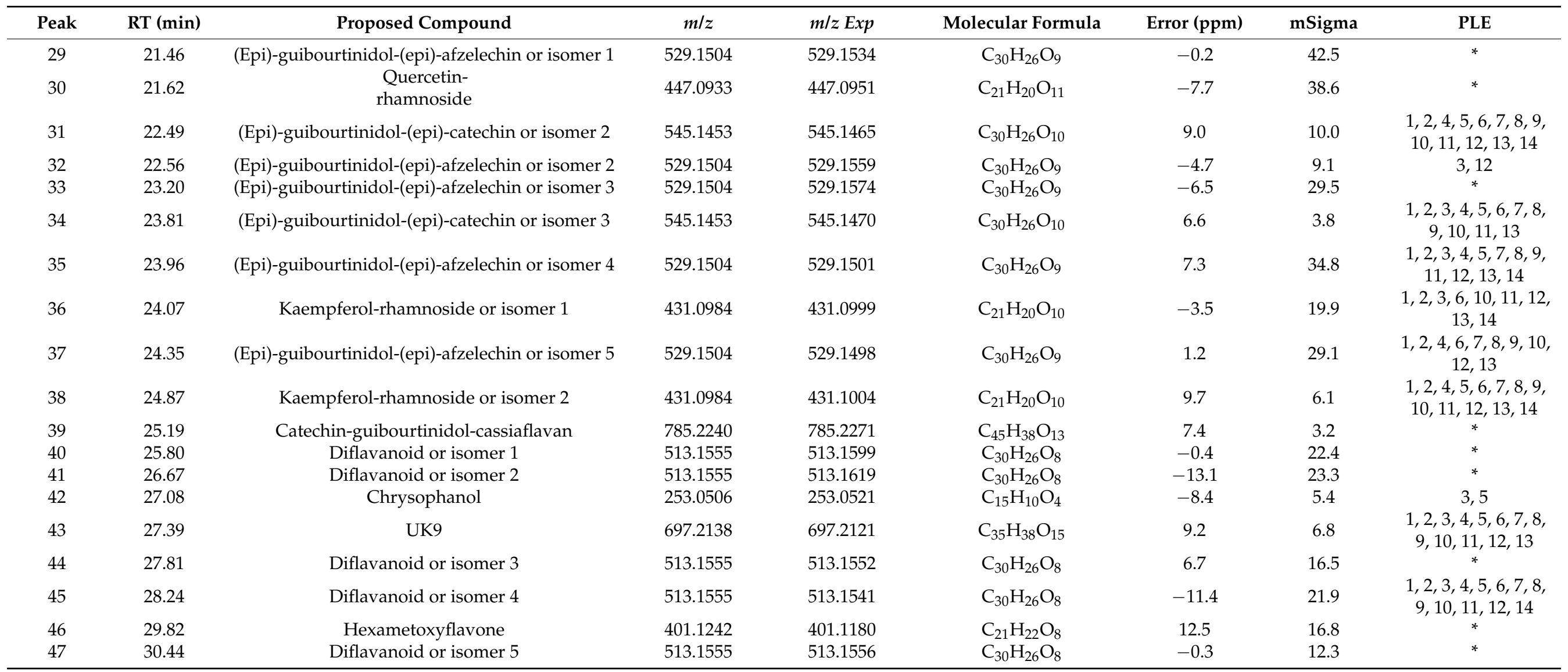

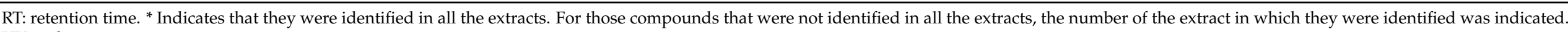
UK, unknown. 


\subsubsection{Disaccharides}

Peak 1, with $m / z 341$ and molecular formula $\mathrm{C}_{12} \mathrm{H}_{22} \mathrm{O}_{11}$, was identified as sucrose. Indeed, this compound has previously been described in other studies about chemical characterization of fruits such as cocoa and grapes [17]. Since the analyzes were developed in reverse phase, this type of compound being more polar than others, eluded at the beginning of the chromatogram.

\subsubsection{Hydroxybenzoic Acids}

The examination of mass spectra and elution profile of compounds in C. grandis seeds revealed two hydroxybenzoic acids (Peaks 2 and 3), respectively identified as galloyl glucoside and its derivative, according to the literature [18]. These compounds were previously described in Sclerocarya birrea, which belongs to the same division (magnoliophyta) and class (magnoliopsida) of $C$. grandis.

\subsubsection{Flavonoids}

Compounds belonging to this chemical group were the major identified phenolics. Indeed, this family has widely been described in other Cassia families [19]. In this particular case, within this group, four different subclasses of compounds have been detected: flavonols, flavanols, flavanones and proanthocyanidins, in addition to a derivative of flavones.

The flavanols subclass included Peaks 17, 27, 30,36 and 38. Peak 17, at retention time of $16.47 \mathrm{~min}$, which displayed $\mathrm{m} / \mathrm{z}$ at 449 , was detected in all extraction conditions. It was identified as astilbin, a compound also described in Cassia bakeriana [20]. Peak 27 was detected in all conditions except to PLE 2, and it was determined to be quercetin-3-glucoside, being confirmed with the commercial standard. In the case of Peak 30, $\mathrm{m} / \mathrm{z} 447$ and molecular formula $\mathrm{C}_{21} \mathrm{H}_{20} \mathrm{O}_{11}$, it was identified as quercetin-rhamnoside. This chemical compound was also identified in Cassia abbreviate [19]. Peaks 36 and 38, both with $\mathrm{m} / z 431$ and the same molecular formula $\mathrm{C}_{21} \mathrm{H}_{20} \mathrm{O}_{10}$, were proposed as kaempferol-rhamnoside or isomer [20].

Peaks 9, 11, 16, 22, 25, 40, 41, 44, 45 and 47 were characterized as flavanols. Peak 9 , which was recovered under all extraction conditions, was proposed as theaflavin [19]. Peaks 11 and 16 were identified, respectively, as catechin and (epi)-catechin [19], and these identifications were also confirmed thanks to commercial standards. Peaks 22 and 25 showed the same mass spectrum, generating the same molecular formula and being identified as (epi)-afzelechin or isomer [19]. However, it was important to remark that Peak 22 appeared in all extraction conditions, but Peak 25 was only detected in PLE 11 and PLE 12. Peaks $40,41,44,45$ and 47 , gave the same $\mathrm{m} / \mathrm{z}$ at 513 and generated the same formula $\left(\mathrm{C}_{30} \mathrm{H}_{26} \mathrm{O}_{8}\right)$, being identified as diflavanoid or isomer. These chemical compounds were reported as flavanol derivatives [21].

With regard to flavanones, Peaks 18 and 20 were characterized as pinocembrin-7neohesperidoside and pinocembrin-7-rutinoside, respectively [22-25]. Their chemical structure was a flavanone (pinocembrin) linked to two different disaccharides (neohesperidoside and rutinoside). These compounds were characterized in the species Litchi chinensis, Euphorbia decipiens and Ziziphora clinopodioides, which belong to the same division and to the same $C$. grandis class.

Peak 46, with retention time of $29.83 \mathrm{~min}$ and $\mathrm{m} / \mathrm{z}$ 401, was identified as hexamethoxyflavone, a derivative of flavones. This compound has been described in Citrus and Murraya [26-28], which belong to the same division and class of $C$. grandis.

Finally, the subclass of proanthocyanidins included Peaks 8, 12, 13, 14, 21, 23, 29, 31, 32, $33,34,35,37$ and 39 . Peaks 8 and 12 were detected in all extraction conditions. Their spectra provided the same $\mathrm{m} / \mathrm{z}$ and molecular formula, being characterized as (epi)-gallocatechin(epi)-catechin (prodelphinidin B3) or its isomers according to the literature [18]. Peak 13 with $m / z 579$ and molecular formula $\mathrm{C}_{30} \mathrm{H}_{27} \mathrm{O}_{12}$, was proposed as procyanidin derivative, which was previously described in Cassia fistula [29]. Peak 14, which was present in all extraction conditions except to PLE 12 and PLE 14, was identified as (epi)-catechin-(epi)- 
catechin (proanthocyanidin B2) according to the literature [19]. Peak 21 was also detected in all extraction conditions and it was proposed as cassanidin A [19]. Peaks 23, 31 and 34 were identified as (epi)-guibourtinidol-(epi)-catechin or its isomers, and Peaks 29, 32, 33, 35 and 37 as (epi)-guibourtinidol-(epi)-afzelechin or its isomers [19]. The last of the phenolic compounds (Peak 39) was identified as catechin-guibourtinidol-cassiaflavan [19].

\subsubsection{Other Polar Compounds}

In relation to other non-phenolic polar compounds, Peak 27, within steroids, was characterized as physalin A [30]. These authors reported the presence of this compound in Physalis alkekengi, which belongs to the magnoliophyta division and to the magnoliopsida class as well as C. grandis. Finally, quinones family included Peak 41, at $\mathrm{m} / \mathrm{z} 253$ and molecular formula $\mathrm{C}_{15} \mathrm{H}_{10} \mathrm{O}_{4}$. It was identified as chrysophanol, previously described in Cassia tora [31].

\subsection{Quantification of Polar Compounds in C. grandis Seed PLE Extracts by HPLC-ESI-TOF-MS}

In order to quantify the amount of polar compounds present in C. grandis seed, six calibration curves were prepared using gallic acid, catechin, epi-catechin, epigallocatechingallate, quercetin-3-glucoside and kaempferol-rutinoside (Table 3). Calibration curves showed good linearity between the different concentration ranges depending on the analyte studied. In all cases, the linearity of calibration curves was better than 0.99 . The concentration of the phenolic compounds present in the extracts was calculated using the individual area obtained by HPLC-ESI-TOF-MS analyzes of each compound and interpolating in the corresponding calibration curve. For this purpose, the calibration curves of the available commercial standard or those with a similar structure were used for each phenolic compound. Hydroxybenzoic acids were quantified using the gallic acid calibration curve. Catechin standard was used to quantify this compound as well as the rest of the flavanols present in the extracts. (Epi)-catechin was quantified with its own commercial standard. Theaflavin derivative, as well as the flavanones pinocembrin-7-neohesperidoside and pinocembrin-7-rutinoside, were quantified with kaempferol-rutinoside.

Table 3. Calibration curves used in the quantification of phenolic compounds.

\begin{tabular}{cccc}
\hline Pattern & Calibration Range $\mathbf{( m g / L )}$ & Calibration Curve & $\boldsymbol{R}^{\mathbf{2}}$ \\
\hline Gallic acid & $1-150$ & $\mathrm{y}=23,395 \mathrm{x}-37,644$ & 0.9926 \\
Catechin & $0.5-20$ & $\mathrm{y}=262,318 \mathrm{x}+23,166$ & 0.9963 \\
Epi-catechin & $0.5-50$ & $\mathrm{y}=287,543 \mathrm{x}+575,127$ & 0.9925 \\
Epigallocatechin-gallate & $0.5-150$ & $\mathrm{y}=82,849 \mathrm{x}+198,670$ & 0.9918 \\
Quercetin-3-glucoside & $0.5-20$ & $\mathrm{y}=457,785 \mathrm{x}+340,216$ & 0.9916 \\
Kaempferol-rutinoside & $0.5-150$ & $\mathrm{y}=115,620 \mathrm{x}+754,772$ & 0.996 \\
\hline
\end{tabular}

Within flavonols, quercetin-3-glucoside and quercetin-rhamnoside were quantified with the quercetin-3-glucoside calibration curve. Kaempferol-rhamnoside was quantified with the standard kaempferol-rutinoside.

The derivative of flavones (hexamethoxyflavone) had a structure similar to catechin, with the difference that its hydroxyl groups were methylated. Due to this similarity, it was quantified with this commercial standard. The same calibration curve was used to quantify the diflavanoids present in the extracts. Finally, all the proanthocyanidins were quantified using the epigallocatechin-gallate calibration curve.

Table 4 showed the yield and the total polar compound for all PLE extracts. With regard to the yield, these results pointed out that these values were within those described for this technique when it was applied to other plant matrices [7,32]. The extraction conditions with the highest yield were PLE $14\left(200{ }^{\circ} \mathrm{C}, 50 \% \mathrm{EtOH}, 12.5 \mathrm{~min}\right)$, PLE $9\left(110^{\circ} \mathrm{C}\right.$, $50 \% \mathrm{EtOH}, 12.5 \mathrm{~min})$ and PLE $8\left(110^{\circ} \mathrm{C}, 50 \% \mathrm{EtOH}, 12.5 \mathrm{~min}\right)$. The extraction conditions PLE 8 and PLE 9 were the central points of the design by presenting the same values of the 
independent variables. For both conditions, the results were similar $(28.45 \%$ and $29.91 \%$, respectively), concluding the reproducibility of the extraction conditions.

Table 4. Extraction yield and quantitative results of PLE central composite $2^{3}$ experimental design expressed in $\mathrm{mg}$ compound/g extract of $C$. grandis seed $(\mathrm{X} \pm \mathrm{SD})$.

\begin{tabular}{ccc}
\hline Experimental Design Condition & Yield (\%) & $\begin{array}{c}\text { Total Polar Compound (mg } \\
\text { Compound/g Extract) }\end{array}$ \\
\hline PLE 1 & 4.44 & $262 \pm 4$ \\
PLE 2 & 3.82 & $236 \pm 1$ \\
PLE 3 & 5.16 & $87 \pm 4$ \\
PLE 4 & 19.9 & $266 \pm 3$ \\
PLE 5 & 3.14 & $136 \pm 1$ \\
PLE 6 & 11.15 & $200 \pm 2$ \\
PLE 7 & 20.19 & $327 \pm 5$ \\
PLE 8 & 28.45 & $286 \pm 5$ \\
PLE 9 & 29.91 & $279 \pm 2$ \\
PLE 10 & 4.82 & $349 \pm 2$ \\
PLE 11 & 15.68 & $217 \pm 7$ \\
PLE 12 & 23.51 & $114 \pm 2$ \\
PLE 13 & 3.64 & $271 \pm 12$ \\
PLE 14 & 29.97 & $46.8 \pm 0.6$ \\
\hline
\end{tabular}

Based on the results obtained, it can be noted that in general, the application of elevated temperatures above $100{ }^{\circ} \mathrm{C}$ combined with percentages equal to or greater than $50 \%$ of ethanol and long times (12 $\mathrm{min}$ ) resulted in higher yields. In effect, the diffusivity of the solvent increases with increasing temperature, as it has been described in the literature [33]. However, it was important to consider that an increase in temperature can affect to thermolabile compounds such as phenolic compounds [32].

The total phenolic content (Table 4) and total hydroxybenzoic acids, flavanols, flavonols, flavanones, flavones, and proanthocyanidins/prodelphinidisns (Tables 5 and 6) were estimated as the sum of the individual phenolic compound belonging to each family. These concentrations were expressed in $\mathrm{mg}$ analyte/g extract. The range of total phenolic content obtained under different PLE conditions was similar to those described in the literature for plant phenolic extracts obtained by advanced extraction techniques [34,35].

As it can be seen, PLE 1 condition $\left(40^{\circ} \mathrm{C}, 15 \% \mathrm{EtOH}, 20 \mathrm{~min}\right)$ was the best combination in the extraction of hydroxybenzoic acid family. Flavanol, flavone and flavanone families were extracted in greater amount with the conditions applied in PLE $10\left(40^{\circ} \mathrm{C}, 85 \% \mathrm{EtOH}\right.$, $20 \mathrm{~min}$ ). Flavanols had high concentrations in almost all extraction conditions, as did proanthocyanidins, although in the latter, the highest concentration reached in the PLE 7 extract $\left(110{ }^{\circ} \mathrm{C}, 50 \% \mathrm{EtOH}, 3 \mathrm{~min}\right)$ could be highlighted. 
Table 5. Concentration of phenolic compounds in PLE extracts, ordered by families and expressed in mg compound/g extract (X \pm SD)

\begin{tabular}{|c|c|c|c|c|c|c|c|}
\hline & PLE 1 & PLE 2 & PLE 3 & PLE 4 & PLE 5 & PLE 6 & PLE 7 \\
\hline \multicolumn{8}{|c|}{ Hydroxybenzoic Acids } \\
\hline Galloyl glucoside & $25 \pm 5$ & $11.1 \pm 0.6$ & $11.7 \pm 0.7$ & $13.4 \pm 0.9$ & $16.1 \pm 0.4$ & $14 \pm 1$ & $16 \pm 1$ \\
\hline Galloyl glucoside derivative & $2.2 \pm 0.1$ & ND & $2.36 \pm 0.05$ & $1.8 \pm 0.1$ & $3.4 \pm 0.1$ & $1.7 \pm 0.3$ & $2.1 \pm 0.3$ \\
\hline Total hydroxybenzoic acids & $27 \pm 5$ & $11.1 \pm 0.6$ & $14 \pm 1$ & $15.1 \pm 0.9$ & $19.6 \pm 0.4$ & $15 \pm 1$ & $18 \pm 1$ \\
\hline \multicolumn{8}{|c|}{ Flavanols } \\
\hline Theaflavin derivative & $0.72 \pm 0.02$ & $1.12 \pm 0.03$ & $0.163 \pm 0.005$ & $0.86 \pm 0.04$ & $0.249 \pm 0.004$ & $0.69 \pm 0.02$ & $1.03 \pm 0.02$ \\
\hline Catechin & ND & ND & $1.01 \pm 0.09$ & $2.3 \pm 0.1$ & $1.25 \pm 0.03$ & ND & ND \\
\hline (Epi)-afzelechin or isomer 1 & $3.2 \pm 0.5$ & $2.1 \pm 0.2$ & $1.77 \pm 0.06$ & $4.0 \pm 0.1$ & $2.4 \pm 0.1$ & $2.2 \pm 0.1$ & $4.7 \pm 0.2$ \\
\hline (Epi)-afzelechin or isomer 2 & ND & ND & ND & ND & ND & ND & ND \\
\hline Diflavanoid or isomer 1 & $14 \pm 1$ & $11.4 \pm 0.4$ & $3.0 \pm 0.1$ & $15.9 \pm 0.6$ & $6.2 \pm 0.2$ & $11.8 \pm 0.3$ & $10.3 \pm 0.2$ \\
\hline Diflavanoid or isomer 2 & $11.5 \pm 0.5$ & $8.2 \pm 0.4$ & $1.94 \pm 0.02$ & $9.35 \pm 0.03$ & $3.1 \pm 0.1$ & $8.1 \pm 0.4$ & $13.6 \pm 0.1$ \\
\hline Diflavanoid or isomer 3 & $1.41 \pm 0.06$ & $1.09 \pm 0.08$ & $0.78 \pm 0.02$ & $3.3 \pm 0.2$ & $1.26 \pm 0.05$ & $1.04 \pm 0.02$ & $2.54 \pm 0.06$ \\
\hline Diflavanoid or isomer 4 & $0.18 \pm 0.02$ & $0.22 \pm 0.01$ & $0.197 \pm 0.003$ & $0.99 \pm 0.08$ & $0.23 \pm 0.01$ & $0.20 \pm 0.01$ & $0.476 \pm 0.006$ \\
\hline Diflavanoid or isomer 5 & $2.01 \pm 0.07$ & $1.80 \pm 0.04$ & $0.236 \pm 0.006$ & $1.78 \pm 0.06$ & $0.404 \pm 0.004$ & $1.98 \pm 0.06$ & $4.1 \pm 0.1$ \\
\hline Total flavanols & $41 \pm 1$ & $33 \pm 1$ & $11.2 \pm 0.3$ & $46 \pm 1$ & $18.1 \pm 0.4$ & $31.8 \pm 0.9$ & $45.2 \pm 0.3$ \\
\hline Astilbin & $0.69 \pm 0.04$ & $0.30 \pm 0.03$ & $0.066 \pm 0.004$ & $0.70 \pm 0.05$ & $0.18 \pm 0.01$ & $0.30 \pm 0.02$ & $1.08 \pm 0.05$ \\
\hline Quercentin-3-glucoside & $1.86 \pm 0.08$ & ND & $0.29 \pm 0.02$ & $2.03 \pm 0.06$ & $0.49 \pm 0.03$ & $0.66 \pm 0.01$ & $2.71 \pm 0.1$ \\
\hline Quercetin-rhamnoside & $2.1 \pm 0.2$ & $0.91 \pm 0.05$ & $0.37 \pm 0.01$ & $2.07 \pm 0.09$ & $0.91 \pm 0.05$ & $1.23 \pm 0.09$ & $2.8 \pm 0.1$ \\
\hline $\begin{array}{l}\text { Kaempferol-rhamnoside or } \\
\text { isomer } 1\end{array}$ & $1.8 \pm 0.1$ & $2.74 \pm 0.05$ & $0.26 \pm 0.01$ & ND & ND & $1.9 \pm 0.1$ & ND \\
\hline $\begin{array}{l}\text { Kaempferol-rhamnoside or } \\
\text { isomer } 2\end{array}$ & $2.5 \pm 0.2$ & $2.5 \pm 0.2$ & ND & $1.13 \pm 0.06$ & $0.56 \pm 0.02$ & $2.2 \pm 0.1$ & $2.10 \pm 0.06$ \\
\hline Total flavonols & $9.0 \pm 0.3$ & $6.5 \pm 0.2$ & $1.00 \pm 0.02$ & $5.94 \pm 0.07$ & $2.15 \pm 0.03$ & $6.3 \pm 0.2$ & $8.7 \pm 0.2$ \\
\hline \multicolumn{8}{|c|}{ Flavanones } \\
\hline $\begin{array}{c}\text { Pinocembrin } \\
\text { 7-neohesperidoside }\end{array}$ & $18 \pm 2$ & $24.9 \pm 0.4$ & $3.7 \pm 0.2$ & $15.1 \pm 0.2$ & $5.7 \pm 0.2$ & $13.7 \pm 0.3$ & $19 \pm 1$ \\
\hline Pinocembrin 7-rutinoside & $25 \pm 1$ & $35.9 \pm 0.9$ & $7.7 \pm 0.1$ & $20.8 \pm 0.6$ & $13.5 \pm 0.5$ & $20.5 \pm 0.4$ & $26 \pm 1$ \\
\hline Total flavanones & $43 \pm 3$ & $61 \pm 1$ & $11.4 \pm 0.3$ & $36.0 \pm 0.7$ & $19.1 \pm 0.7$ & $34.3 \pm 0.6$ & $45 \pm 2$ \\
\hline \multicolumn{8}{|c|}{ Flavones } \\
\hline Hexametoxyflavone & $2.9 \pm 0.1$ & $18.4 \pm 0.8$ & $1.38 \pm 0.09$ & $1.55 \pm 0.04$ & $2.8 \pm 0.1$ & $9.1 \pm 0.3$ & $3.00 \pm 0.08$ \\
\hline Total flavones & $2.9 \pm 0.1$ & $18.4 \pm 0.8$ & $1.38 \pm 0.09$ & $1.55 \pm 0.04$ & $2.8 \pm 0.1$ & $9.1 \pm 0.3$ & $3.00 \pm 0.08$ \\
\hline
\end{tabular}


Table 5. Cont.

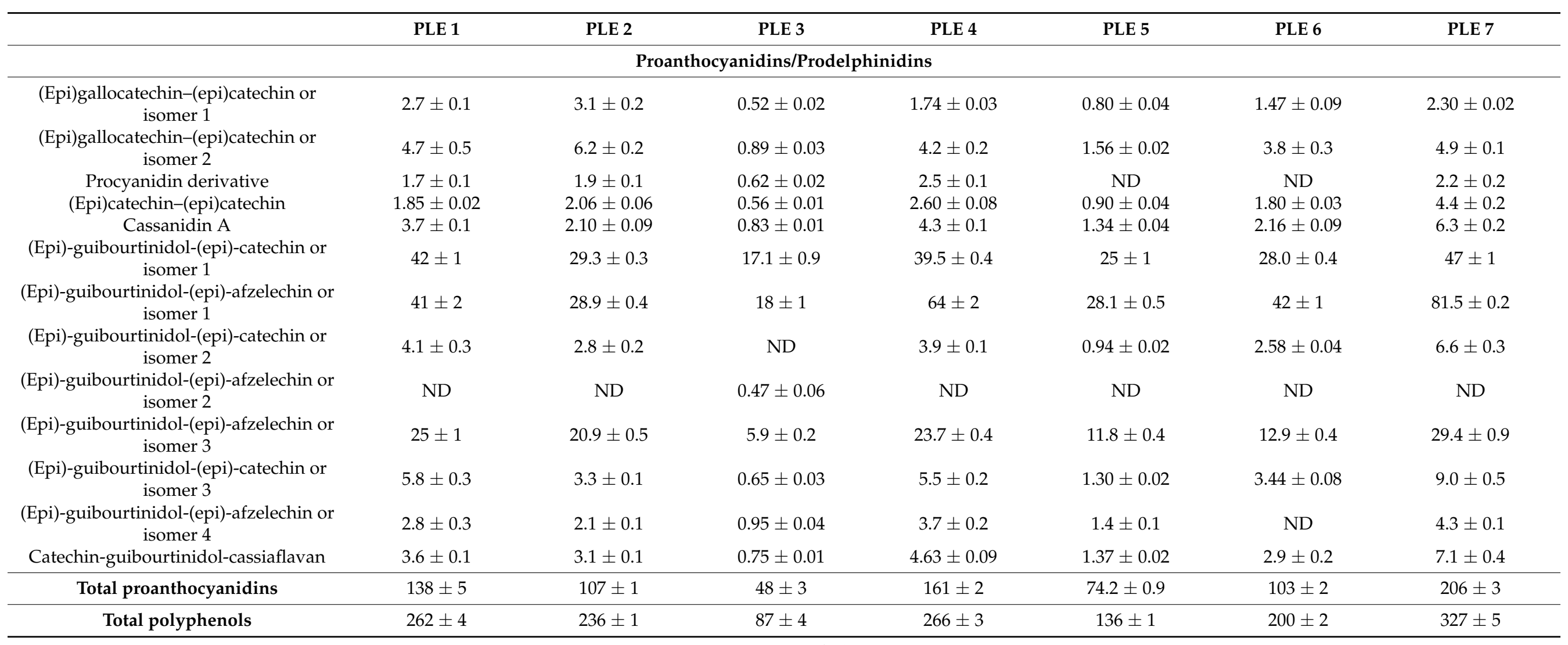


Table 6. Concentration of phenolic compounds in PLE extracts, ordered by families and expressed in mg compound/g extract (X \pm SD).

\begin{tabular}{|c|c|c|c|c|c|c|c|}
\hline & PLE 8 & PLE 9 & PLE 10 & PLE 11 & PLE 12 & PLE 13 & PLE 14 \\
\hline \multicolumn{8}{|c|}{ Hydroxybenzoic Acids } \\
\hline Galloyl glucoside & $15.4 \pm 0.5$ & $14.6 \pm 0.9$ & $20 \pm 1$ & $17 \pm 1$ & $8.6 \pm 0.4$ & $18 \pm 2$ & $2.97 \pm 0.07$ \\
\hline Galloyl glucoside derivative & $2.5 \pm 0.2$ & ND & ND & $3.1 \pm 0.2$ & ND & ND & ND \\
\hline Total hydroxybenzoic acids & $17.9 \pm 0.4$ & $14.6 \pm 0.9$ & $20 \pm 1$ & $20 \pm 1$ & $8.6 \pm 0.4$ & $18 \pm 2$ & $2.97 \pm 0.07$ \\
\hline \multicolumn{8}{|c|}{ Flavanols } \\
\hline Theaflavin derivative & $0.74 \pm 0.04$ & $0.93 \pm 0.02$ & $1.48 \pm 0.01$ & $0.69 \pm 0.01$ & $0.41 \pm 0.01$ & $0.84 \pm 0.03$ & $0.08 \pm 0.01$ \\
\hline Catechin & $1.49 \pm 0.08$ & $1.69 \pm 0.02$ & ND & $4.3 \pm 0.3$ & $2.5 \pm 0.3$ & ND & $0.82 \pm 0.02$ \\
\hline (Epi)-catechin & $9.2 \pm 0.4$ & $8.5 \pm 0.3$ & $10.0 \pm 0.3$ & $7.0 \pm 0.5$ & $2.2 \pm 0.2$ & $7.1 \pm 0.9$ & $1.05 \pm 0.06$ \\
\hline (Epi)-afzelechin or isomer 1 & $3.8 \pm 0.2$ & $4.4 \pm 0.2$ & $3.5 \pm 0.2$ & $4.5 \pm 0.3$ & $2.31 \pm 0.07$ & $3.1 \pm 0.2$ & $0.9 \pm 0.1$ \\
\hline (Epi)-afzelechin or isomer 2 & ND & ND & ND & $1.14 \pm 0.05$ & $0.86 \pm 0.02$ & ND & ND \\
\hline Diflavanoid or isomer 1 & $17.4 \pm 0.7$ & $16.6 \pm 0.3$ & $16.9 \pm 0.6$ & $10.5 \pm 0.7$ & $4.0 \pm 0.1$ & $10.0 \pm 0.2$ & $1.95 \pm 0.07$ \\
\hline Diflavanoid or isomer 2 & $11.5 \pm 0.2$ & $10.7 \pm 0.2$ & $12.1 \pm 0.1$ & $5.7 \pm 0.2$ & $2.06 \pm 0.08$ & $9.2 \pm 0.2$ & $1.19 \pm 0.04$ \\
\hline Diflavanoid or isomer 3 & $2.7 \pm 0.1$ & $2.74 \pm 0.09$ & $1.61 \pm 0.08$ & $2.1 \pm 0.1$ & $1.7 \pm 0.1$ & $1.00 \pm 0.04$ & $0.67 \pm 0.02$ \\
\hline Diflavanoid or isomer 4 & $0.75 \pm 0.02$ & $0.78 \pm 0.03$ & $0.49 \pm 0.02$ & $0.57 \pm 0.02$ & $0.35 \pm 0.02$ & ND & $0.14 \pm 0.02$ \\
\hline Diflavanoid or isomer 5 & $2.9 \pm 0.1$ & $3.03 \pm 0.06$ & $3.6 \pm 0.1$ & $1.48 \pm 0.03$ & $0.76 \pm 0.05$ & $1.59 \pm 0.08$ & $0.22 \pm 0.01$ \\
\hline Total flavanols & $51 \pm 1$ & $49.4 \pm 0.4$ & $49 \pm 1$ & $38 \pm 2$ & $17.2 \pm 0.8$ & $33 \pm 1$ & $7.05 \pm 0.01$ \\
\hline Astilbin & $0.79 \pm 0.03$ & $0.718 \pm 0.005$ & $0.66 \pm 0.03$ & $0.54 \pm 0.05$ & $0.10 \pm 0.01$ & $0.54 \pm 0.06$ & $0.040 \pm 0.004$ \\
\hline Quercentin-3-glucoside & $2.24 \pm 0.1$ & $2.11 \pm 0.02$ & $0.81 \pm 0.05$ & $1.71 \pm 0.02$ & $0.91 \pm 0.02$ & $1.8 \pm 0.2$ & $0.36 \pm 0.03$ \\
\hline Quercetin-rhamnoside & $2.29 \pm 0.04$ & $2.24 \pm 0.03$ & $1.74 \pm 0.02$ & $1.59 \pm 0.08$ & $0.63 \pm 0.04$ & $2.0 \pm 0.2$ & $0.27 \pm 0.01$ \\
\hline Kaempferol-rhamnoside or isomer 1 & ND & ND & $3.6 \pm 0.2$ & $1.35 \pm 0.01$ & $0.89 \pm 0.02$ & $1.75 \pm 0.06$ & $0.32 \pm 0.01$ \\
\hline Kaempferol-rhamnoside or isomer 2 & $1.58 \pm 0.03$ & $1.42 \pm 0.02$ & $4.3 \pm 0.2$ & $1.52 \pm 0.04$ & $1.06 \pm 0.03$ & $2.46 \pm 0.03$ & $0.37 \pm 0.01$ \\
\hline Total flavonols & $6.9 \pm 0.1$ & $6.488 \pm 0.005$ & $11.1 \pm 0.5$ & $6.72 \pm 0.06$ & $3.59 \pm 0.09$ & $8.6 \pm 0.5$ & $1.36 \pm 0.06$ \\
\hline \multicolumn{8}{|c|}{ Flavanones } \\
\hline Pinocembrin 7-neohesperidoside & $16.2 \pm 0.2$ & $16.0 \pm 0.4$ & $29.7 \pm 0.3$ & $18.0 \pm 0.4$ & $13.0 \pm 0.3$ & $21 \pm 2$ & $3.40 \pm 0.08$ \\
\hline Pinocembrin 7-rutinoside & $22.0 \pm 0.3$ & $21.6 \pm 0.2$ & $46 \pm 3$ & $21.5 \pm 0.8$ & $16.0 \pm 0.3$ & $26 \pm 2$ & $4.9 \pm 0.2$ \\
\hline Total flavanones & $38.2 \pm 0.5$ & $37.6 \pm 0.5$ & $75 \pm 3$ & $40 \pm 1$ & $29.0 \pm 0.7$ & $47 \pm 5$ & $8.3 \pm 0.2$ \\
\hline \multicolumn{8}{|c|}{ Flavones } \\
\hline Hexametoxyflavone & $2.09 \pm 0.06$ & $2.1 \pm 0.1$ & $28.1 \pm 0.8$ & $2.26 \pm 0.09$ & $2.64 \pm 0.04$ & $3.0 \pm 0.2$ & $3.0 \pm 0.2$ \\
\hline Total flavones & $2.09 \pm 0.06$ & $2.1 \pm 0.1$ & $28.1 \pm 0.8$ & $2.26 \pm 0.09$ & $2.64 \pm 0.04$ & $3.0 \pm 0.2$ & $3.0 \pm 0.2$ \\
\hline
\end{tabular}


Table 6. Cont

\begin{tabular}{|c|c|c|c|c|c|c|c|}
\hline & PLE 8 & PLE 9 & PLE 10 & PLE 11 & PLE 12 & PLE 13 & PLE 14 \\
\hline \multicolumn{8}{|c|}{ Proanthocyanidins/Prodelphinidins } \\
\hline $\begin{array}{c}\text { (Epi)gallocatechin-(epi)catechin or } \\
\text { isomer } 1\end{array}$ & $1.83 \pm 0.08$ & $1.85 \pm 0.05$ & $4.0 \pm 0.2$ & $2.2 \pm 0.1$ & $1.20 \pm 0.04$ & $3.0 \pm 0.2$ & $0.381 \pm 0.007$ \\
\hline $\begin{array}{c}\text { (Epi)gallocatechin-(epi)catechin or } \\
\text { isomer } 2\end{array}$ & $4.3 \pm 0.2$ & $4.49 \pm 0.09$ & $7.4 \pm 0.4$ & $4.8 \pm 0.3$ & $2.63 \pm 0.09$ & $5.2 \pm 0.4$ & $0.80 \pm 0.02$ \\
\hline Procyanidin derivative & $1.63 \pm 0.06$ & $1.59 \pm 0.04$ & $2.8 \pm 0.2$ & ND & $2.8 \pm 0.2$ & $1.50 \pm 0.05$ & ND \\
\hline (Epi)catechin-(epi)catechin & $3.2 \pm 0.1$ & $3.17 \pm 0.06$ & $3.173 \pm 0.06$ & $0.86 \pm 0.02$ & ND & $1.9 \pm 0.1$ & ND \\
\hline Cassanidin A & $5.0 \pm 0.2$ & $5.1 \pm 0.1$ & $2.95 \pm 0.09$ & $1.85 \pm 0.06$ & $0.77 \pm 0.04$ & $3.32 \pm 0.02$ & $0.45 \pm 0.01$ \\
\hline $\begin{array}{c}\text { (Epi)-guibourtinidol-(epi)-catechin or } \\
\text { isomer } 1\end{array}$ & $47 \pm 1$ & $41.8 \pm 0.1$ & $38.7 \pm 0.5$ & $29.7 \pm 0.8$ & $14.7 \pm 0.2$ & $44 \pm 2$ & $6.3 \pm 0.4$ \\
\hline $\begin{array}{l}\text { (Epi)-guibourtinidol-(epi)-afzelechin or } \\
\text { isomer } 1\end{array}$ & $67.5 \pm 0.6$ & $71.1 \pm 0.6$ & $65 \pm 1$ & $43 \pm 3$ & $22.1 \pm 0.5$ & $61 \pm 2$ & $10.8 \pm 0.3$ \\
\hline $\begin{array}{c}\text { (Epi)-guibourtinidol-(epi)-catechin or } \\
\text { isomer } 2\end{array}$ & $5.0 \pm 0.2$ & $4.75 \pm 0.07$ & $4.4 \pm 0.1$ & $2.1 \pm 0.1$ & $0.83 \pm 0.04$ & $3.6 \pm 0.2$ & $0.45 \pm 0.01$ \\
\hline $\begin{array}{c}\text { (Epi)-guibourtinidol-(epi)-afzelechin or } \\
\text { isomer } 2\end{array}$ & ND & ND & ND & ND & $1.33 \pm 0.03$ & ND & ND \\
\hline $\begin{array}{c}\text { (Epi)-guibourtinidol-(epi)-afzelechin or } \\
\text { isomer } 3\end{array}$ & $25.1 \pm 0.2$ & $18.3 \pm 0.3$ & $25.1 \pm 0.5$ & $18.0 \pm 0.5$ & $5.7 \pm 0.3$ & $25.9 \pm 0.3$ & $3.74 \pm 0.05$ \\
\hline $\begin{array}{c}\text { (Epi)-guibourtinidol-(epi)-afzelechin or } \\
\text { isomer } 4\end{array}$ & $3.66 \pm 0.03$ & $3.8 \pm 0.2$ & ND & $2.9 \pm 0.1$ & $2.2 \pm 0.2$ & $2.04 \pm 0.09$ & $0.77 \pm 0.02$ \\
\hline \multirow{2}{*}{$\begin{array}{c}\text { Catechin-guibourtinidol-cassiaflavan } \\
\text { (Epi)gallocatechin-(epi)catechin or } \\
\text { isomer } 1\end{array}$} & $1.14 \pm 0.03$ & $1.16 \pm 0.05$ & $1.316 \pm 0.009$ & ND & $0.46 \pm 0.02$ & $0.51 \pm 0.05$ & ND \\
\hline & $5.5 \pm 0.1$ & $5.4 \pm 0.2$ & $4.8 \pm 0.2$ & $2.19 \pm 0.08$ & $0.83 \pm 0.03$ & $3.27 \pm 0.04$ & $0.532 \pm 0.008$ \\
\hline Total proanthocyanidins & $171 \pm 3$ & $169 \pm 1$ & $164 \pm 2$ & $110 \pm 4$ & $53.5 \pm 0.6$ & $160 \pm 5$ & $24.1 \pm 0.7$ \\
\hline Total pplyphenols & $286 \pm 5$ & $279 \pm 2$ & $349 \pm 2$ & $217 \pm 7$ & $114 \pm 2$ & $271 \pm 12$ & $46.8 \pm 0.6$ \\
\hline
\end{tabular}




\subsection{PLE Extraction Design Optimization}

Extraction yields and total phenolic compounds values obtained by PLE conditions were integrated into the experimental design with Statgraphics Centurion 15.0 software. Table 7 shows the analysis of the proposed model showing linear, quadratic and interactions effects among independent variables $\left(\mathrm{X}_{1}\right.$ :Temperature, $\mathrm{X}_{2}$ :EtOH and $\mathrm{X}_{3}$ :Extration time) on the variable responses extraction yield $\left(\mathrm{Y}_{1}\right)$ and total phenolic compounds $\left(\mathrm{Y}_{2}\right)$.

Table 7. Variance analysis of the proposed experimental model.

\begin{tabular}{|c|c|c|c|c|c|}
\hline \multicolumn{6}{|c|}{$Y_{1}$} \\
\hline Variable & Sum of Squares & d.f. & Mean Square & F-Ratio & $p$-Value \\
\hline $\mathrm{X}_{1}:$ Temperature & 252.032 & 1 & 252.032 & 236.47 & 0.0299 \\
\hline $\mathrm{X}_{2}: \mathrm{EtOH}$ & 4.353 & 1 & 4.353 & 4.08 & 0.2925 \\
\hline $\mathrm{X}_{3}$ :Extration time & 10.6513 & 1 & 10.6513 & 9.99 & 0.1950 \\
\hline $\mathrm{X}_{1} \mathrm{X}_{1}$ & 22.2878 & 1 & 22.2878 & 20.01 & 0.1371 \\
\hline$X_{1} X_{2}$ & 4.92866 & 1 & 4.92866 & 4.62 & 0.2771 \\
\hline$x_{1} x_{3}$ & 6.20363 & 1 & 6.20363 & 5.82 & 0.2502 \\
\hline$x_{2} x_{2}$ & 668.137 & 1 & 668.137 & 626.89 & 0.0254 \\
\hline$x_{2} x_{3}$ & 0.946107 & 1 & 0.946107 & 0.89 & 0.5189 \\
\hline$x_{3} x_{3}$ & 28.7276 & 1 & 28.7276 & 26.95 & 0.1211 \\
\hline Lack-of-fit & 72.3088 & 6 & 24.1029 & 22.61 & 0.1938 \\
\hline Pure error & 1.0658 & 1 & 1.0658 & & \\
\hline Total (corr.) & 1469.87 & 13 & & & \\
\hline$R^{2}$ & & & 0.95008 & & \\
\hline \multicolumn{6}{|c|}{$Y_{2}$} \\
\hline Variable & Sum of Squares & d.f. & Mean Square & F-Ratio & $p$-Value \\
\hline $\mathrm{X}_{1}:$ Temperature & $31,277.3$ & 1 & $31,277.3$ & 1177.03 & 0.0173 \\
\hline $\mathrm{X}_{2}: \mathrm{EtOH}$ & $24,795.9$ & 1 & $24,795.9$ & 933.12 & 0.0196 \\
\hline $\mathrm{X}_{3}$ :Extration time & 399.097 & 1 & 399.097 & 15.02 & 0.1704 \\
\hline $\mathrm{X}_{1} \mathrm{X}_{1}$ & $31,802.3$ & 1 & $31,802.3$ & 1196.79 & 0.0185 \\
\hline$x_{1} x_{2}$ & 984.21 & 1 & 984.21 & 37.04 & 0.1037 \\
\hline$x_{1} x_{3}$ & $16,413.9$ & 1 & $16,413.9$ & 617.69 & 0.0236 \\
\hline$X_{2} X_{2}$ & $11,195.3$ & 1 & $11,195.3$ & 421.30 & 0.0324 \\
\hline$x_{2} x_{3}$ & 47.0042 & 1 & 47.0042 & 1.77 & 0.4104 \\
\hline$x_{3} x_{3}$ & 2415.8 & 1 & 2415.8 & 90.91 & 0.0533 \\
\hline Lack-of-fit & 3833.34 & 6 & 1277.78 & 48.09 & 0.1231 \\
\hline Pure error & 26.5731 & 1 & 26.5731 & & \\
\hline Total (corr.) & 109,034 & 13 & & & \\
\hline$R^{2}$ & & & 0.96569 & & \\
\hline
\end{tabular}

Extraction yield $\left(\mathrm{Y}_{1}\right)$ and total phenolic compounds $\left(\mathrm{Y}_{2}\right)$.

The analysis of independent variables was adjusted to a $95 \%$ of confidence level, so the value of $R^{2}$ for each of the variables indicated that the model, thus adjusted, explained 95.0\% and $96.6 \%$ of the variability in yield and total phenolic compounds variables, respectively. To verify if the selected model was adequate to explain the observed data, or if a more complicated model should be used, the lack-of-fit test was also included. Since the $p$ value for the lack-of-fit in the ANOVA table was greater than 0.05 for both variables, the model seemed to be adequate for the data observed at a confidence level of $95.0 \%$. The significant effects of each independent variable were those which had a $p$-value equal to or less than 0.05. Therefore, for those variables whose quadratic effects or interactions with other variables did not present significant effects, they were eliminated from the model's adjustment equation [7].

The fitted equations of the model for each response variables are described below (Equation (2)):

$$
\begin{gathered}
Y 1=-13.7306+0.108894 X_{1}+0.931317 X_{2}+0.141351 X_{3}-0.00933134 X_{2}^{2} \\
Y 2=-128.608+3.97862 X_{1}+5.54721 X_{2}+11.4992 X_{3}-0.0162721 X_{1}^{2}-0.112334 X_{1} X_{3}-0.0376946 X_{2}^{2}
\end{gathered}
$$


Equation (2): Equations of the fitted model: (a) extraction yield (Y1); and (b) content of total phenolic compounds (Y2).

Concerning yield, the main variables that affected this response were temperature and the quadratic effect of the percentage of ethanol used in the extraction. With regard to the phenolic compounds, temperature and ethanol were statistically significant. However, in relation to the quadratic effects and the interactions between independent variables, the response variable of total phenolic compounds was significantly affected by the quadratic effects of temperature and ethanol, as well as the interactions of temperature with extraction time.

Figure 2 showed the individual and multiple response surface plots.

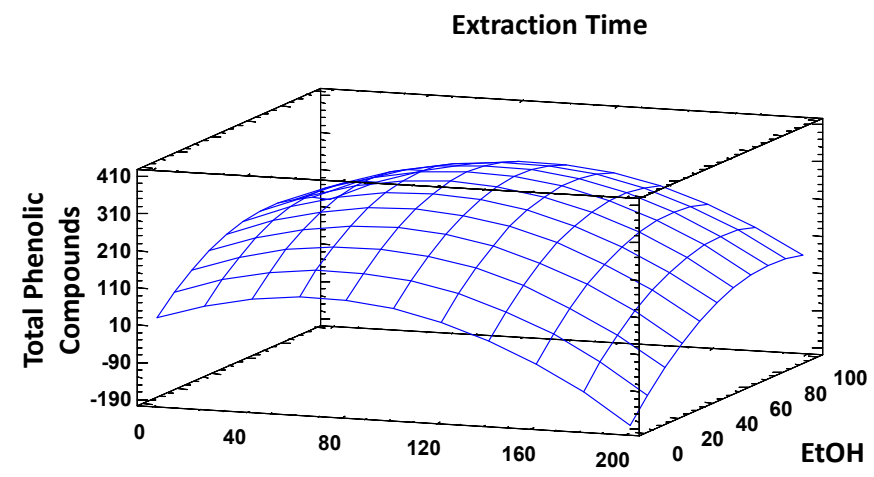

(a)

Temperature
Extraction Time

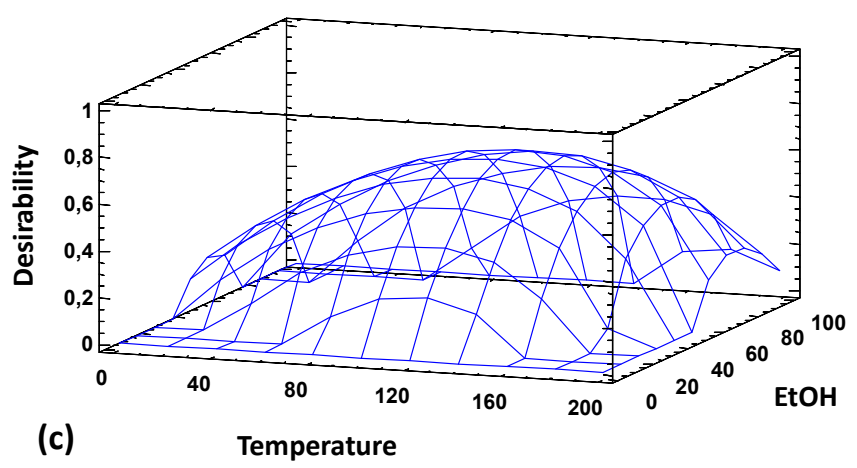

Extraction Time

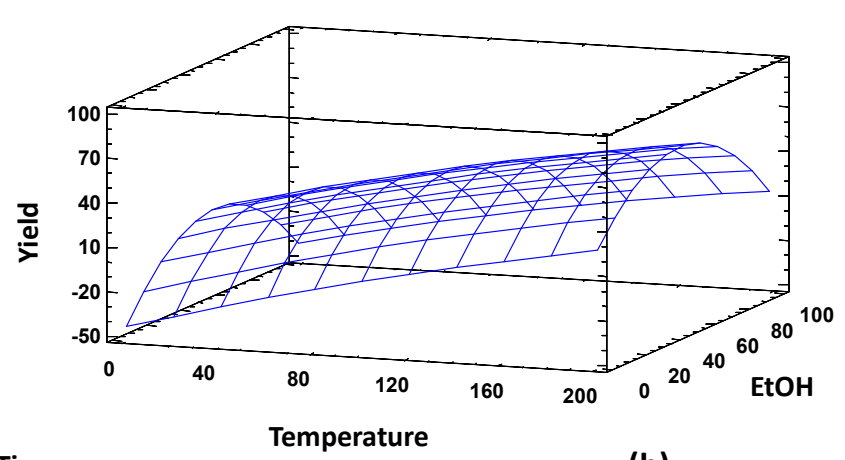

(b)

Figure 2. Surface response graphs: (a) phenolic compounds; (b) extraction yield; and (c) optimization of multiple responses.

Finally, Table 8 included the predictable results according to the optimum conditions provided by the model for each of the independent variables.

Table 8. Theoretical values of independent variable to maximize the response variables provided by the model.

\begin{tabular}{ccccc}
\hline Factors & Temperature $\mathbf{X}_{\mathbf{1}}\left({ }^{\circ} \mathbf{C}\right)$ & EtOH $\mathbf{X}_{\mathbf{2}}(\mathbf{\%})$ & Time $\mathbf{X}_{\mathbf{3}}$ (min) & Theoretical Optimum \\
\cline { 1 - 4 } Variable Response & & & 22 & $34.4 \%$ \\
Yield & 200 & 49.8 & 22 & $363 \mathrm{mg} / \mathrm{g}$ \\
TPC & 46.3 & 73.8 & 3 & Yield $=25.7 \%$ \\
Multiple response & 146.5 & 54.8 & $\mathrm{TPC}=281 \mathrm{mg} / \mathrm{g}$ \\
\hline
\end{tabular}

TPC: total phenolic compounds mg/g extract.

The theoretical-optimum yield value established by the experimental design determined that to maximize the extraction yield, the following PLE conditions could be applied: $49.8 \%$ ethanol, $200{ }^{\circ} \mathrm{C}$, and an extraction time of $22 \mathrm{~min}$. The proposed ethanol percentage 
was within the experimental region of the model. The PLE extractions carried out at the laboratory reported that the highest yield values were obtained with PLE 8, PLE9 and PLE14 conditions (Tables 1 and 4). In all of these conditions, 50\% ethanol was combined with high temperatures, up to $200{ }^{\circ} \mathrm{C}$ in the highest yield condition (29.97\%), being this value the operational limit of the PLE device. This temperature corresponds to the maximum value proposed by the model to maximize the extraction yield. It is important to remark that this variable was tested in its fully operational range allowed by the device, and consequently, in a practical application it would be not possible to increase the maximum value established by the proposed design. With respect to the extraction time, its theoretical optimum value to maximize extraction yield could be obtained with a total run time of $22 \mathrm{~min}$ in combination with the other factors. Since this value was the maximum time applied in the experimental runs, it could indicate that the model did not cover all experimental region for this independent variable. However, it could be taken into account that extraction time effects were not significant to this response variable (Table 7). Indeed, the experimental results pointed out that the extraction yield obtained for PLE4 and PLE7 were similar, 19.9 and $20.19 \%$, respectively. These experimental runs were carried out at the same temperature $\left(110{ }^{\circ} \mathrm{C}\right)$ and percentage of ethanol $(50 \%)$, but different extraction times: $22 \mathrm{~min}$ (PLE4) and $3 \mathrm{~min}$ (PLE7). In addition to that, reduction of the extraction time from 22 min (PLE4) to 12.5 min (PLE8 and PLE9) and keeping constant the rest of the experimental variables increased the extraction yield from 19.8 to $28.45-29.91 \%$ (PLE8 and PLE9, respectively).

Concerning the total phenolic compounds, the theoretical factors proposed to maximize this response variable were $46.3{ }^{\circ} \mathrm{C}, 73.8 \%$ ethanol and an extraction time of $22 \mathrm{~min}$ (Table 8). These proposed conditions were similar to the PLE 10 extraction condition: $40{ }^{\circ} \mathrm{C}, 85 \%$ ethanol and an extraction time of $20 \mathrm{~min}$, for which a response variable value of $349 \mathrm{mg} / \mathrm{g}$ of extract was obtained. This value was similar to the theoretical optimum proposed by the model: $363 \mathrm{mg} / \mathrm{g}$ of extract. Analysing the independent variables, both of the theoretical values proposed for temperature and percentage of ethanol were within the experimental region evaluated by the proposed model. As it has been described above, temperature as well as percentage of ethanol showed significant effect in the recovery of this kind of phytochemicals by PLE. On the other hand, the better extraction time to maximize this response seems to be in the limit of the experimental region. Statistical analysis of the design showed that the extraction time was not significant for the phenolic compounds recovery by PLE. In fact, the analysis of the total phenolic content obtained in the experimental runs showed an independent behaviour with respect to the extraction time. For example, PLE4, PLE7, PLE8 and PLE9 were developed at $110{ }^{\circ} \mathrm{C}$ and 50\% EtOH, being the total run time 22, 3, 12.5 and $12.5 \mathrm{~min}$, respectively. All of these conditions provided similar recovery of bioactive compounds (Table 4).

Despite that, extraction time was not significant for both response variables, extraction yield and phenolic compounds did not showed correlation over the PLE experimental conditions evaluated. Therefore, the response variables showed different optimal PLE factors to maximize their recovery from Carao seeds. The main difference was concerning to the temperature values. The analyzed results proposed $200{ }^{\circ} \mathrm{C}$ and $46.3^{\circ} \mathrm{C}$ to maximize the extraction yield and total phenolic content, respectively. Indeed the lower temperature to be applied for the recovering of phenolic compounds could be justify due to it is well-known that an increase in temperature can affect to thermolabile compounds such as phenolic compounds [32]. In order to maximize both responses, a multiple response analysis was carried out. The results pointed out that the theoretical values of extraction yield and phenolic compounds were minor that those proposed by the individual analysis. 


\section{Conclusions}

The proposed extraction system using PLE allowed to obtain 14 extracts under different extraction conditions delimited by the technical limits of the PLE extractor. Chemical characterization of these extracts allowed detecting 47 compounds. The HPLC-ESI-TOF-MS analytical platform made it possible to identify these compounds, using the information provided by the mass spectrometer, as well as the scientific literature. In the same way, the proposed analytical methodology allowed the quantification of the identified phenolic compounds, belonging to the families of hydroxybenzoic acids, flavonoids (flavonols, flavanols, flavanones and proanthocyanidins) in addition to a derivative of flavones. Finally, the proposed surface response model pointed out the effect of the independent variables (temperature, percentage of ethanol and time) on the response variables: yield and total phenolic compounds. Statistical analysis of the results confirmed that the proposed model is appropriate for explaining the obtained results and allowed estimating the optimal theoretical values for each of the response variables based on optimal extraction conditions. An extraction process is feasible to the functional food industry when the process accomplished the extraction of bioactive compounds and reasonable amounts allowing the minimum solvent, time and energy consumptions. This methodology could be useful for producers to obtain phenolic compounds-enriched ingredients. The combination of this methodology with stabilization and formulation techniques could be applied to obtain functional ingredient with application to food antioxidants as well as to nutraceutical products.

Supplementary Materials: The following are available online at https://www.mdpi.com/2304-815 8/10/2/398/s1, Figure S1: MS spectra of the proposed compounds, including the peak numbers of Table 2 (Peaks 1-24). Figure S2: MS spectra of the proposed compounds, including the peak numbers of Table 2 (Peaks 25-47).

Author Contributions: J.L.-S., I.B.-L.: conceptualization; J.A.M.F., L.L.-S.: data curation; J.A.M.F., L.L.-S.: formal analysis; J.L.-S., M.N.-A.: funding acquisition; J.A.M.F., L.L.-S., IBS: investigation; J.L.S., I.B.-L.: methodology; A.S.-C., J.L.-S.: project administration; M.N.-A., A.S.-C., J.L.-S.: supervision; J.A.M.F., L.L.-S.: roles / writing—original draft; J.L.-S., I.B.-L., A.S.-C., M.N.-A.: writing—review and editing. All authors have read and agreed to the published version of the manuscript.

Funding: This research was funded by Coimbra Group Scholarship Programme for Young Professors and Researchers from Latin American Universities, Centro de Iniciativas de Cooperación al desarrollo (CICODE), Research Group AGR279 Ciencias de la Alimentación y Nutrición (University of Granada, Spain) and Universidad Nacional de Agricultura, Catacamas, Honduras.

Data Availability Statement: All the data generated by this research have been included in the article. Anyway, for any assitance it is possible to contact with the corresponding author.

Conflicts of Interest: The authors declare no conflict of interest.

\section{References}

1. Joven, J.; Micol, V.; Segura-Carretero, A.; Alonso-Villaverde, C.; Menéndez, J.A. Polyphenols and the Modulation of Gene Expression Pathways: Can We Eat Our Way Out of the Danger of Chronic Disease? Crit. Rev. Food Sci. Nutr. 2014, 54, 985-1001. [CrossRef]

2. Frankel, E.; Bakhouche, A.; Lozano-Sánchez, J.; Segura-Carretero, A.; Fernández-Gutiérrez, A. Literature Review on Production Process to Obtain Extra Virgin Olive Oil Enriched in Bioactive Compounds. Potential Use of Byproducts as Alternative Sources of Polyphenols. J. Agric. Food Chem. 2013, 61, 5179-5188. [CrossRef] [PubMed]

3. Sánchez-Marzo, N.; Lozano-Sánchez, J.; Cádiz-Gurrea, M.D.L.L.; Herranz-López, M.; Micol, V.; Segura-Carretero, A. Relationships Between Chemical Structure and Antioxidant Activity of Isolated Phytocompounds from Lemon verbena. Antioxidants 2019, 8, 324. [CrossRef]

4. Villegas-Aguilar, M.D.C.; Fernández-Ochoa, Á.; Cádiz-Gurrea, M.D.L.L.; Pimentel-Moral, S.; Lozano-Sánchez, J.; ArráezRomán, D.; Segura-Carretero, A. Pleiotropic Biological Effects of Dietary Phenolic Compounds and their Metabolites on Energy Metabolism, Inflammation and Aging. Molecules 2020, 25, 596. [CrossRef] [PubMed]

5. Muñoz Jauregui, A.M.; Ramos Escudero, F. Componentes Fenólicos de la Dieta y sus Propiedades Biomedicinales—Phenolics Compounds of the Diet and his Biomedicinal Properties. Horiz. Med. 2007, 7, 23-38.

6. Leyva-Jiménez, F.J.; Lozano-Sánchez, J.; Cádiz-Gurrea, M.D.L.L.; Arráez-Román, D.; Segura-Carretero, A. Functional Ingredients based on Nutritional Phenolics. A Case Study against Inflammation: Lippia Genus. Nutrients 2019, 11, 1646. [CrossRef] 
7. Leyva-Jiménez, F.J.; Lozano-Sánchez, J.; Borrás-Linares, I.; Arráez-Román, D.; Segura-Carretero, A. Comparative Study of Conventional and Pressurized Liquid Extraction for Recovering Bioactive Compounds from Lippia citriodora Leaves. Food. Res. Int. 2018, 109, 213-222. [CrossRef]

8. Pimentel-Moral, S.; Borrás-Linares, I.; Lozano-Sánchez, J.; Alañón, M.E.; Arráez-Román, D.; Segura-Carretero, A. Pressurized GRAS Solvents for the Green Extraction of Phenolic Compounds from Hibiscus sabdariffa Calyces. Food Res. Int. 2020, 137, 109466. [CrossRef]

9. García, P.; Fredes, C.; Cea, I.; Lozano-Sánchez, J.; Leyva-Jiménez, F.j.; Robert, P.; Vergara, C.; Jimenez, P. Recovery of Bioactive Compounds from Pomegranate (Punica granatum L.) Peel Using Pressurized Liquid Extraction. Foods 2021, 10, 203. [CrossRef] [PubMed]

10. Cea-Pavez, I.; Lozano-Sánchez, J.; Borrás-Linares, I.; Nuñez, H.; Robert, P.; Segura-Carretero, A. Obtaining an Extract Rich in Phenolic Compounds from Olive Pomace by Pressurized Liquid Extraction. Molecules 2019, 24, 3108. [CrossRef]

11. Cádiz-Gurrea, M.D.L.L.; Lozano-Sánchez, J.; Fernández-Ochoa, Á.; Segura-Carretero, A. Enhancing the Yield of Bioactive Compounds from Sclerocarya birrea Bark by Green Extraction Approaches. Molecules 2019, 24, 966. [CrossRef]

12. Lozano-Sánchez, J.; Castro-Puyana, M.; Mendiola, J.A.; Segura-Carretero, A.; Cifuentes, A.; Ibáñez, E. Recovering Bioactive Compounds from Olive Oil Filter Cake by Advanced Extraction Techniques. Int. J. Mol. Sci. 2014, 15, 16270-16283. [CrossRef]

13. Nastić, N.; Lozano-Sánchez, J.; Borrás-Linares, I.; Švarc-Gajić, J.; Segura-Carretero, A. New Technological Approaches for Recovering Bioactive Food Constituents from Sweet Cherry (Prunus avium L.) Stems. Phytochem. Anal. 2020, 31, 119-130.

14. Nastić, N.; Borrás-Linares, I.; Lozano-Sánchez, J.; Švarc-Gajić, J.; Segura-Carretero, A. Comparative Assessment of Phytochemical Profiles of Comfrey (Symphytum officinale L.) Root Extracts Obtained by Different Extraction Techniques. Molecules 2020, 25, 837. [CrossRef]

15. Joshi, H.; Kapoor, V.P. Cassia grandis Linn. f. Seed Galactomannan: Structural and Crystallographical Studies. Carbohydr. Res. 2003, 338, 1907-1912. [CrossRef]

16. Macía Fuentes, J.A.; Fernández, I.M.; Fernández, H.Z.; Sánchez, J.L.; Alemán, R.S.; Navarro-Alarcon, M.; Borrás-Linares, I.; Saravia Maldonado, S.A. Quantification of Bioactive Molecules, Minerals and Bromatological Analysis in Carao (Cassia grandis). J. Agric. Sci. 2020, 12, 88-94.

17. Cádiz-Gurrea, M.D.L.L.; Borrás-Linares, I.; Lozano-Sánchez, J.; Joven, J.; Fernández-Arroyo, S.; Segura- Carretero, A. Cocoa and Grape Seed Byproducts as a Source of Antioxidant and Anti-inflammatory Proanthocyanidins. Int. J. Mol. Sci. 2017, 18, 376 [CrossRef] [PubMed]

18. Jiménez-Sánchez, C.; Lozano-Sánchez, J.; Gabaldón-Hernández, J.A.; Segura-Carretero, A.; Fernández- Gutiérrez, A. RP-HPLCESI-QTOF/MS2 based Strategy for the Comprehensive Metabolite Profiling of Sclerocarya birrea (Marula) Bark. Ind. Crops Prod. 2015, 71, 214-234. [CrossRef]

19. Sobeh, M.; Mahmoud, M.F.; Abdelfattah, M.A.O.; Cheng, H.; El-Shazly, A.M.; Wink, M. A Proanthocyanidin-rich Extract from Cassia abbreviata Exhibits Antioxidant and Hepatoprotective Activities In Vivo. J. Ethnopharmacol. 2018, 213, 38-47. [CrossRef]

20. Da Costa Silva, T.; Justino, A.B.; Prado, D.G.; Koch, G.A.; Martins, M.M.; de Souza Santos, P.; Lemos de Morais, S.A.; Goulart, L.R.; Scalon Cunha, L.C.; Ferreira de Sousa, R.M.; et al. Chemical Composition, Antioxidant Activity and Inhibitory Capacity of $\alpha$-Amylase, $\alpha$-Glucosidase, Lipase and Non-Enzymatic Glycation, In Vitro, of the Leaves of Cassia bakeriana Craib. Ind. Crops Prod. 2019, 140, 111641. [CrossRef]

21. Ucar, M.B.; Ucar, G.; Pizzi, A.; Gonultas, O. Characterization of Pinus brutia Bark Tannin by MALDI-TOF MS and 13C NMR. Ind. Crops Prod. 2013, 49, 697-704. [CrossRef]

22. Xu, X.; Xie, H.; Hao, J.; Jiang, Y.; Wei, X. Flavonoid Glycosides from the Seeds of Litchi chinensis. J. Agric. Food Chem. 2011, 59, 1205-1209. [CrossRef] [PubMed]

23. Wang, L.; Lou, G.; Ma, Z.; Liu, X. Chemical Constituents with Antioxidant Activities from Litchi (Litchi chinensis Sonn.) Seeds. Food Chem. 2011, 126, 1081-1087. [CrossRef]

24. Demirkiran, O.; Topcu, G.; Hussain, J.; Uddin Ahmad, V.; Choudhary, M.I. Structure Elucidation of Two New Unusual Monoterpene Glycosides from Euphorbia decipiens, by 1D and 2D NMR Experiments. Magn. Reson. Chem. 2011, 49, 673-677. [CrossRef] [PubMed]

25. Meng, Q.; Li, G.; Luo, B.; Wang, L.; Lu, Y.; Liu, W. Screening and Isolation of Natural Antioxidants from: Ziziphora clinopodioides Lam. with High Performance Liquid Chromatography coupled to a Post-column Ce(IV) Reduction Capacity Assay. RSC Adv. 2016, 6, 62378-62384. [CrossRef]

26. Zhang, J.Y.; Li, N.; Zhou, Y.; Jiang, Y.; Tu, P.F. Simultaneous Qualitative and Quantitative Determination of Major Polymethoxylated Flavonoids in the Leaves of Murraya paniculata by RRLC-DAD-ESI-MSn. Anal. Methods 2012, 4, 3399-3406. [CrossRef]

27. Xing, T.T.; Zhao, X.J.; Zhang, Y.D.; Li, Y.F. Fast Separation and Sensitive Quantitation of Polymethoxylated Flavonoids in the Peels of Citrus using UPLC-Q-TOF-MS. J. Agric. Food Chem. 2017, 65, 2615-2627. [CrossRef]

28. Zhang, J.; Lu, J.; Zhang, Q.; Dai, L.; Liu, Y.; Tu, P.; Qiao, Y. Simultaneous Screening and Identifying Four Categories of Particular Flavonoids in the Leaves of Murraya exotica L. by HPLC-DAD-ESI-MS-MS. J. Chromatogr. Sci. 2014, 52, 1-12. [CrossRef]

29. Thabit, S.; Handoussa, H.; Roxo, M.; El Sayed, N.S.; de Azevedo, B.C.; Wink, M. Evaluation of Antioxidant and Neuroprotective Activities of Cassia fistula (L.) using the Caenorhabditis elegans model. Peer] 2018, 13, 1-33. [CrossRef]

30. Zheng, Y.; Luan, L.; Chen, Y.; Ren, Y.; Wu, Y. Characterization of Physalins and Fingerprint Analysis for the Quality Evaluation of Physalis alkekengi L. var. franchetii by Ultra-Performance Liquid Chromatography combined with Diode Array Detection and Electrospray Ionization Tandem Mass Spectrometry. J. Pharm. Biomed. Anal. 2012, 71, 54-62. [CrossRef] 
31. Chen, X.; Tong, L.; Chu, Y.; Wang, X.; Zhang, L.; Ma, X.; Zhou, S.; Liu, C. Identification and Characterization of Anthraquinones in Cassia tora L. by Liquid Chromatography connected with Time of Flight Mass Spectrometry and Ion Trap Mass Spectrometry. Asian J. Chem. 2013, 25, 7840-7842. [CrossRef]

32. Figueroa, J.G.; Borrás-Linares, I.; Lozano-Sánchez, J.; Quirantes-Piné, R.; Segura-Carretero, A. Optimization of Drying Process and Pressurized Liquid Extraction for Recovery of Bioactive Compounds from Avocado Peel By-product. Electrophoresis 2018, 39, 1908-1916. [CrossRef] [PubMed]

33. Herrero, M.; Castro-Puyana, M.; Mendiola, J.A.; Ibañez, E. Compressed Fluids for the Extraction of Bioactive Compounds. Trends Anal. Chem. 2013, 43, 67-83. [CrossRef]

34. Pimentel-Moral, S.; Borrás-Linares, I.; Lozano-Sánchez, J.; Arráez-Román, D.; Martínez-Férez, A.; Segura-Carretero, A. MicrowaveAssisted Extraction for Hibiscus sabdariffa Bioactive Compounds. J. Pharm. Biomed. Anal. 2018, 156, 313-322. [CrossRef]

35. Leyva-Jiménez, F.J.; Manca, M.L.; Manconi, M.; Caddeo, C.; Vázquez, J.A.; Lozano-Sánchez, J.; Escribano-Ferrer, E.; ArráezRomán, D.; Segura-Carretero, A. Incorporation of Lippia citriodora Microwave Extract into Total-Green Biogelatin-Phospholipid vesicles to Improve its Antioxidant Activity. Nanomaterials 2020, 10, 765. [CrossRef] [PubMed] 